\begin{abstract}
The commercial development and growth rate of rigid urethane foams has not met the forecasts presented by the chemical industry. Difficulty in meeting building code requirements and specifications established by regutlatory groups coupled with relatively poor comparative economics of applied insulation has retarded the growth and acceptance of many foam products. A review of extended foams systems based on the incorporation of low cost commodity chemicals into foam systems will be presented. These modified systems, while significantly lower in cost, have gained only limited acceptance due to the loss of dimensional stability, lower heat distortion properties, and increased permeability.
\end{abstract}

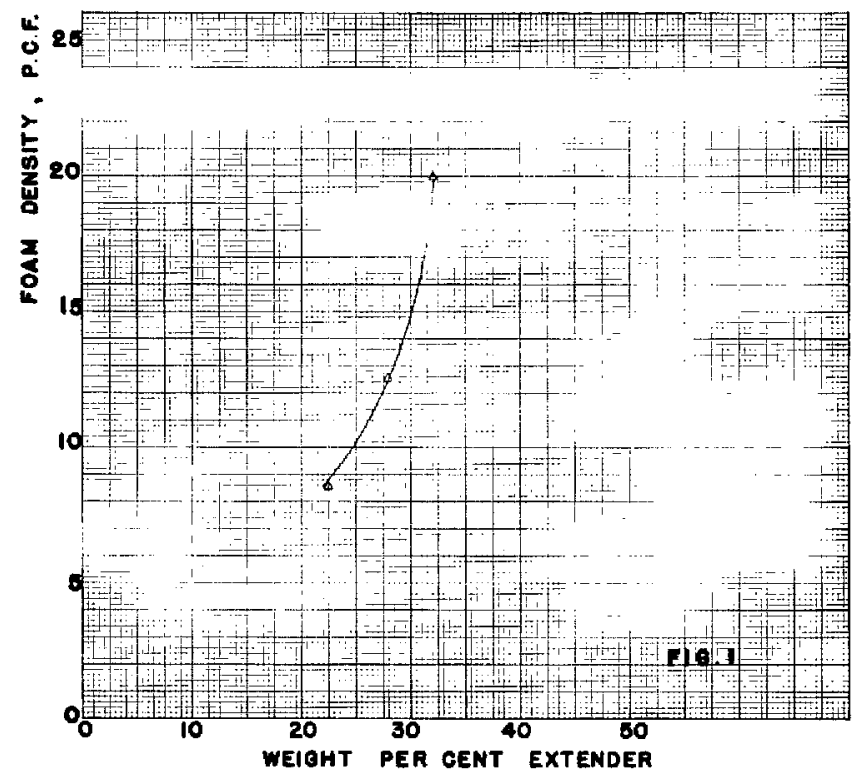

Figure 1. Relationship between foam density and weight percent of lignin.

$\mathbf{R}$ gid urethane foams obtained by the reaction of diisocyanate with hydroxyl containing polyols in the presence of a blowing agent and suitable catalyst system have exhibited high strength to weight properties, low permeability to vapors and liquids, and low thermal conductivity. However, major penetration of these materials into areas governed by such factors as building codes and specifications set by regulatory agencies will not become a reality until the flammability characteristics, permeance properties, and physical strengths are improved.

\section{Extended Foams}

\author{
I. N. Einhorn,
}

Institute of Science and Technology

The University of Michigan,

Ann Arbor, Michigan

SPI INTERNATIONAL

CELLULAR PLASTICS

CONFERENCE 


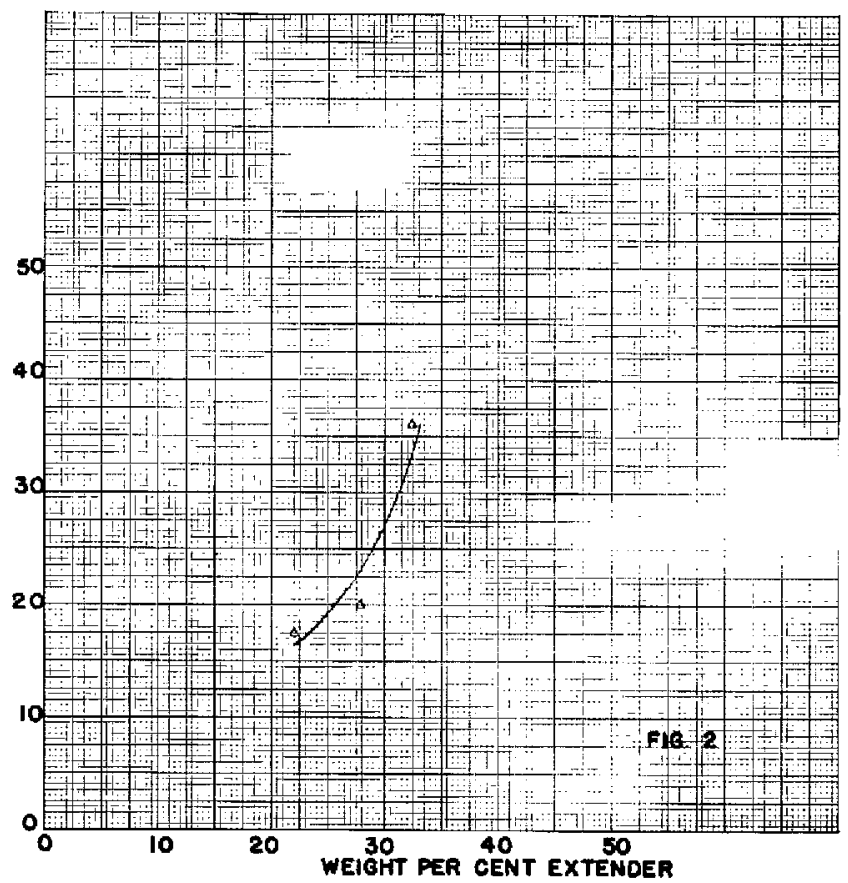

Figure 2. Relationship between strength-weight ratio and weight percent lignin extender.

is shown in Table 1. The physical properties of Vinsol extended rigid urethane foam are illustrated in Table 2.

Crude tall oil has been used as an extender for low density rigid urethane fo:ams. Tall oil is a natural product obtained as a residue from the alkaline or sulfate process of wood pulp manufacture. The primary source of this material is the soft resinous type woods, such as pine and fir, which are used for kraft paper manufacture.

Rigid foams were prepared from crude tall oil, crude p,p' diphenylmethane diisocyanate, nitrogenbased polyether polyols, trichloromonofluoromethane, and a foam stabilizer $(4,5)$. Typical formulations are presented in Table 3 .

Rigid foams having $85-95 \%$ closed cells with low thermal conductivity and fair to moderately good dimensional stability under accelerated humid aging are prepared from the formulations presented in Table 3. Table 4 presents a summary of the physical properties for foams containing different

\section{Table 1. Vinsol Extended Urethane Foam}

PBW \%WT.

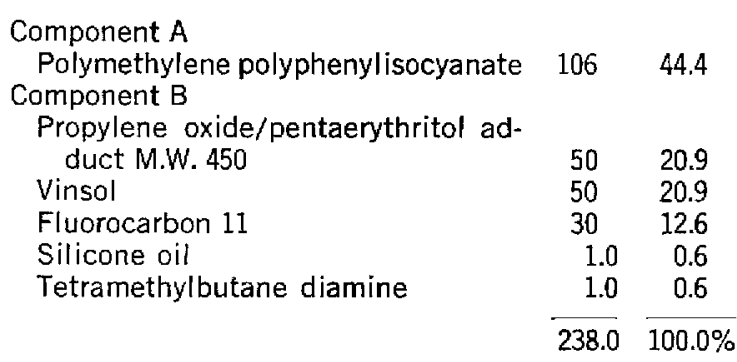

amounts of crude tall oil $(38 \%, 34 \%$, and $30 \%$ by weight of total polymer).

Tall oil pitch (5), tall oil heads (5), and coal tar pitch (6) are examples of other low cost extenders used to modify rigid wrethane foam. Foams based on those extenders while lower in cost per unit volume than conventional systems do not pos-

Table 2. Properties of Vinsol Extended Rigid Urethane Foam

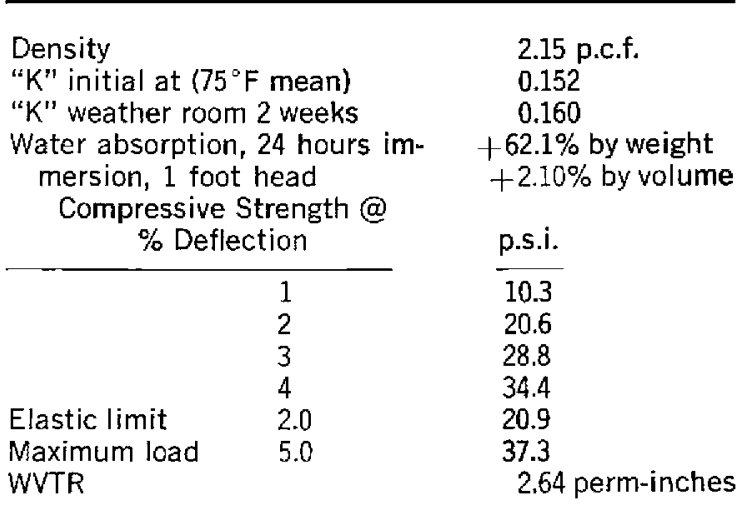

Table 3. Typical Formulations for Rigid Foam Derived From Crude Tall Oil

\begin{tabular}{lrrr}
\hline Formulation & 1 & 2 & 3 \\
\hline $\begin{array}{l}\text { Crude Tall Oil } \\
\text { N,N,N',N'-tetrakis (2-hydroxy propyl) }\end{array}$ & 75 & 70 & 65 \\
$\quad$ ethylenediamine & 25 & 30 & 35 \\
$\begin{array}{l}\text { Crude p, } p^{\prime} \text {-diphenylmehane diisocy- } \\
\quad \text { anate }\end{array}$ & 70 & 80 & 90 \\
Fluorocarbon 11 & 25 & 25 & 25 \\
Silicone stabilizer & 1 & 1 & 1 \\
Index number & 100 & $\frac{100}{100}$ & $\frac{100}{1}$ \\
\hline
\end{tabular}

Table 4. Physical Properties of Rigid Foams Derived From Crude Tall Oil

\begin{tabular}{|c|c|c|c|}
\hline Formulation & 1 & 2 & 3 \\
\hline \multicolumn{4}{|l|}{ Crude tall oil, $\%$ by wt. of } \\
\hline Density, p.c.f. & 2.2 & 2.2 & 2.0 \\
\hline Tensile strength, p.s.i. & $25-35$ & $25-25$ & $25-30$ \\
\hline $\begin{array}{l}\text { Compressive strength at } \\
\text { yield, p.s.i. }\end{array}$ & $15-20$ & $15-20$ & $20-25$ \\
\hline $\begin{array}{l}\text { Closed cell, \% } \\
\text { "K" factor }\left(23^{\circ} \mathrm{C}\right)\end{array}$ & $85-95$ & $85-95$ & $85-95$ \\
\hline Initial & $0.13-0.14$ & $0.13-0.14$ & $0.14-0.15$ \\
\hline 50 days R.T., $50 \%$ R.H. & $0.14-0.15$ & $0.14-0.15$ & $0.15-0.16$ \\
\hline \multicolumn{4}{|l|}{ Dimensional stability, vol. } \\
\hline $\begin{array}{l}\text { Change, } \% 4 \text { WKS.-100 } \mathrm{C} \text {, } \\
\text { ambient humidity }\end{array}$ & $-5-10$ & $-7-10$ & $5-10$ \\
\hline Water absorption, $\mathrm{g} / \mathrm{in}^{3}$ & $0.5-0.8$ & $0.5-1.0$ & $0.5-1.0$ \\
\hline Cell size (cells/inch) & $55-70$ & $55-70$ & $55-70$ \\
\hline
\end{tabular}




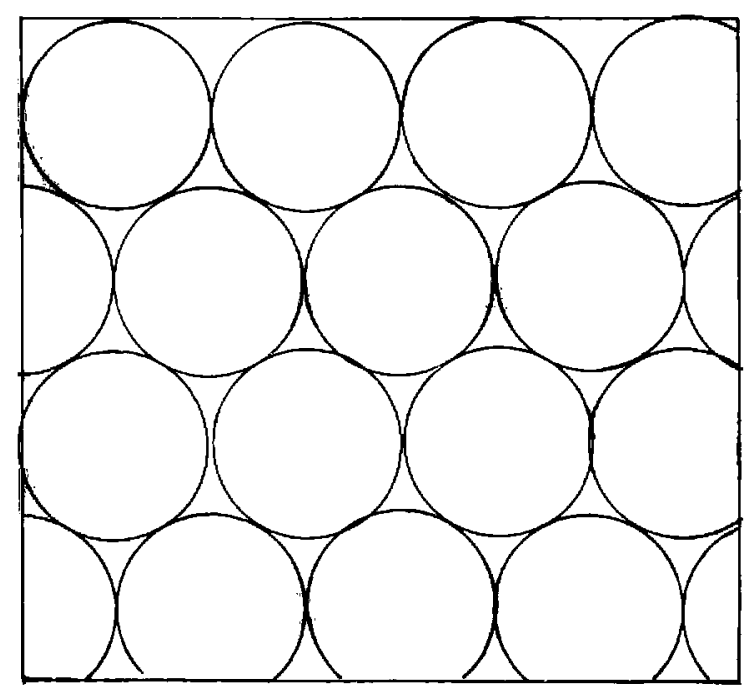

Figure 3. Closest packing of spheres.

sess sufficient dimensional stability to warrant their specification in construction applications.

Thus it is obvious that while a number of low cost chemical by-products may be incorporated in urethane foam systems, the physical properties of such extended foams are degradated, especially with regards to humid aging characteristics.

\section{Foam Composites}

Laboratory evaluation of composites based on low cost organic, as well as non-burning inorganic fillers was initiated.

Composites were prepared incorporating the following fillers: asbestos fibers, cellular glass pellets, excelsior, fibrous glass, glass flake, glass microballoons, glass wool, mica, perlite, phenolic microballoons, polystyrene beads, sand, synthetic fibers, vermiculite, wood fiber.

The preparation of foam composites is dependent upon control of mechanical and chemical variables. The size, configuration, density, surface, thermal properties, and flammability characteristics of the extender must be considered during design of composites. Important interactions occur during processing of composites, thus the foam formulation may require modification to obtain a desirable structure.

\section{Factors Affecting Composite Density}

Extender size-Urethane foam has the tendency to form a skin when in contact with a substrate during expansion. Thus for a given loading volume, small fillers, which possess large surface area will cause greater densification of the foam matrix than will larger fillers with low surface area.

Extender configuration and packing volume-The configuration of the extender will govern the packing volume within the cavity to be filled. The theoretical packing volume for perfect spheres of uniform diameter is approximately $74 \%$ (Figure 3 ). The packing volume may be increased by varying the diameter of the spheres so that the spheres of

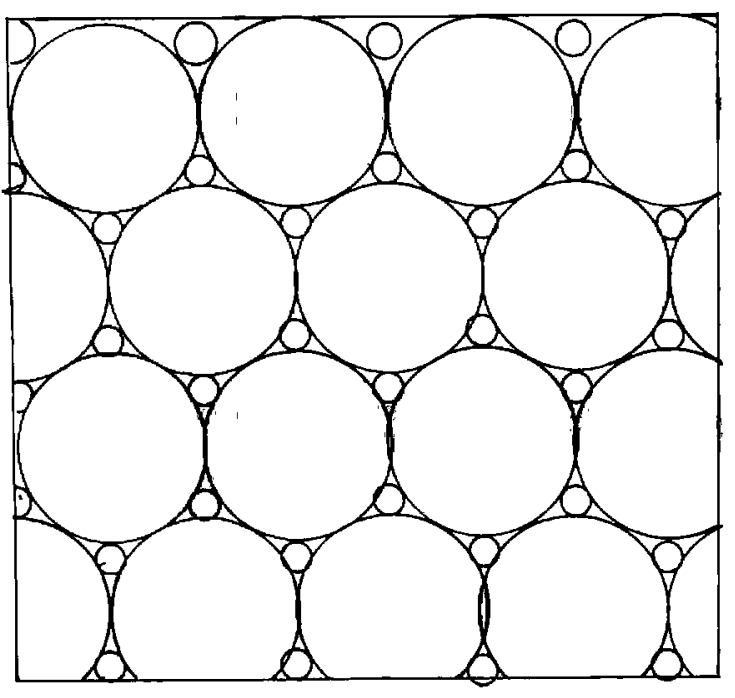

Figure 4. Scientific packing of spheres.

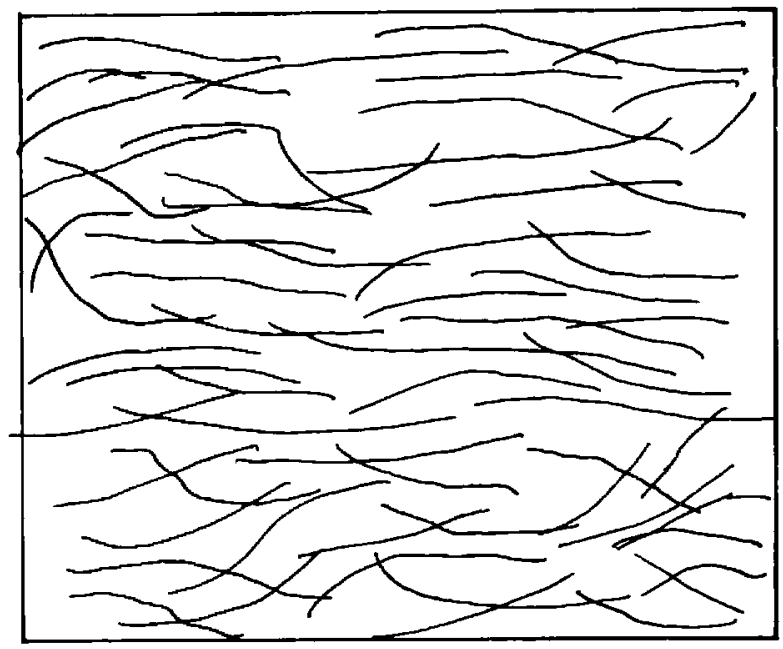

Figure 5. Typical composite cross sections of fiber-like extenders.

smaller diameter fill the interstices created by the packing of the larger spheres (Figure 4).

If the extender is non-spherical in configuration it is probable that only a relatively low volume of filler could be incorporated into the composite structure without encountering major densification of the foam matrix. Figure 5 indicates the typical crosssection encountered when the composite is based on a fiber-like extender.

Extender density-The density of the extender will have an effect upon the density of the foam matrix within the composite. This, however, appears to be of secondary importance and is possibly the result of a series of interactions which include extender size, extender configuration, extender density, extender heat transfer characteristics, etc.

If the extender has an efficient thermal conductivity (low $\mathrm{K}$-factor) it may act as a heat sink as has been demonstrated in the preparation of composites using urethane foam as the matrix. It therefore may become necessary to adjust the foam catalyst level to compensate for loss of exotherm during preparation which would result in a higher matrix density. 


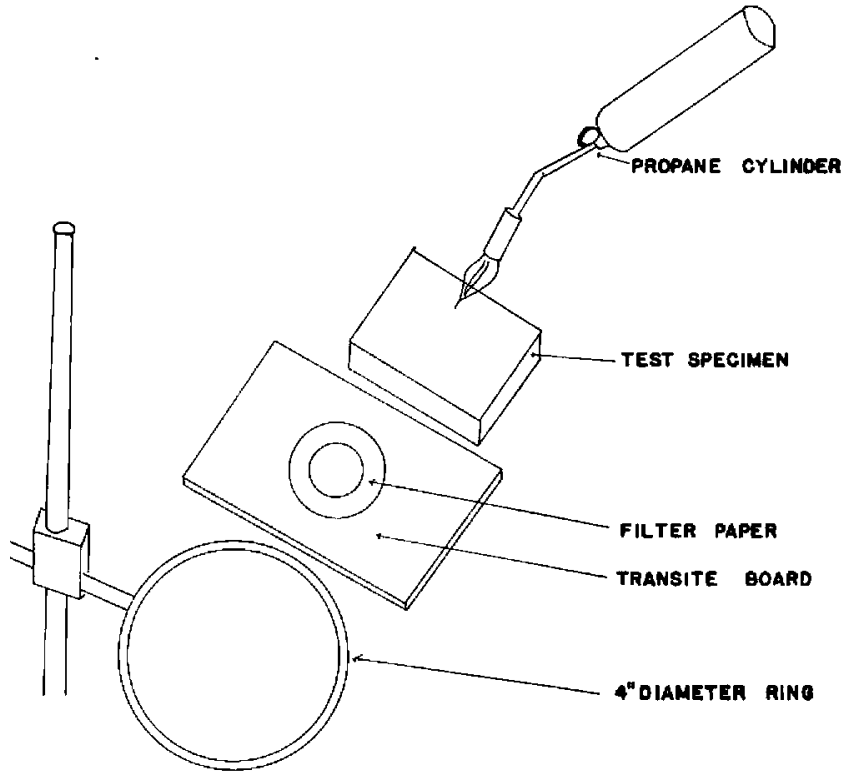

Figure 6. Schematic of Bureau of Mines Apparatus for horizontal test method.

Method of preparation-Several methods have been developed as a means of incorporating an extender into the foaming mass during the processing of composites. These include pre-mixing the extender into one or more of the foam raw materials, injecting the extender into the foaming stream in the mixing chamber, injecting the extender into the foaming mass downstream of the mixing chamber prior to initiation of rise, or injecting the extender into the mold cavity before or after the foaming mass has been introduced.

It may be necessary to modify the foam formulation used as the matrix. In fact a variety of modifications may be made to reduce the density of the matrix and thus obtain a more favorable economic balance. These modifications might include the following:

1. Addition of fluorocarbon blowing agent

2. Adjustment of initiation of rise time to allow for greater "flow-through" of the foaming mass

3. Increase the surface temperature of the extender to reduce density at interface

4. Coat the extender with materials such as catalyst, isocyanate, blowing agent, or other components of the system to reduce the ten-

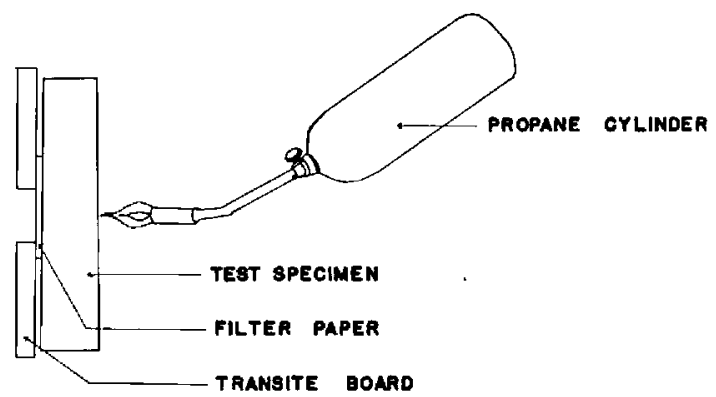

Figure 7. Schematic of Bureau of Mines Apparatus for vertical test.
Table 5. Bureau of Mines Fire Endurance Test (Horizontal Method)

\section{SAMPLE DESCRIPTION}

ENDURANCE TIME

Cellular Plastics

Polystyrene bead board (non S.E.) Expanded polystyrene (non S.E.) Expanded polystyrene (S.E.) Urethane foam (non S.E.)*

Epoxy foam (S.E.)

Urethane foam (S.E.)

Cellular Composites

Styrene bead foam/glass pellet composite

Styrene bead foam/pelletized glass microballoons composite

Urethane foam (non S.E.)*/mica composite

Urethane foam (non S.E.)/glass flake composite

Urethane foam (non S.E.) ${ }^{*} /$ vermicrilite composite

Urethane foam (non S.E.)*/glass flake composite

Urethane foam (non S.E.)*/glass pellet composite

Urethane foam (non S.E.)*/pelletized glass microballoons composite

Urethane foam (S.E.) ${ }^{* *} /$ glass flake composite

Urethane foam $(S . E .)^{\star \star} / g$ lass pellet composite

Urethane foam (S.E.)**/pelletized glass microballoons composite

Miscellaneous Control Samples

Fiber glass board (12.0 p.c.f.)

White pine (25.2 p.c.f.)

$7 \mathrm{sec}$.

$7 \mathrm{sec}$.

$9 \mathrm{sec}$.

$20 \mathrm{sec}$.

$1 \mathrm{~min} .20 \mathrm{sec}$

$19 \mathrm{~min} .20 \mathrm{sec}$.

\section{9 sec.}

$11 \mathrm{sec}$.

20 sec.

$20 \mathrm{sec}$.

5 min. 22 sec.

$39 \mathrm{sec}$.

$10 \mathrm{~min} .40 \mathrm{sec}$.

$10 \mathrm{~min} .48 \mathrm{sec}$.

$3 \mathrm{hr} .+$

$3 \mathrm{hr} .+$

$3 \mathrm{hr} .+$

$7 \mathrm{~min} .45 \mathrm{sec}$. $53 \mathrm{~min} .15 \mathrm{sec}$.

*Urethane foam (TDI, sorbitol adduct, F-11 system) **Urethane foam (polymeric isocyanate, chlorinated polyester polyol, F-11 system)

dency to form a high density skin at the interface.

\section{Properties of Cellular Composites}

Flammability characteristics-Numerous methods exist for the evaluation of the flammability properties of cellular plastics and foam composites. The test developed by the personnel of the Bureau of Mines was employed as a small scale bench method to determine the fire endurance properties of limited size samples.

Horizontal Test-A schematic drawing of the Bureau of Mines apparatus is illustrated in Figure 6. A $6^{\prime \prime} \times 6^{\prime \prime} \times 1$ " specimen is placed upon a transite board as shown in Figure 6 . A piece of laboratory filter paper is placed under the test specimen over the cut-out section of transite. The flame source utilized is a propane burner with a pensil flame 
Table 6. Modified Bureau of Mines Fire Endurance Test (Vertical Method)

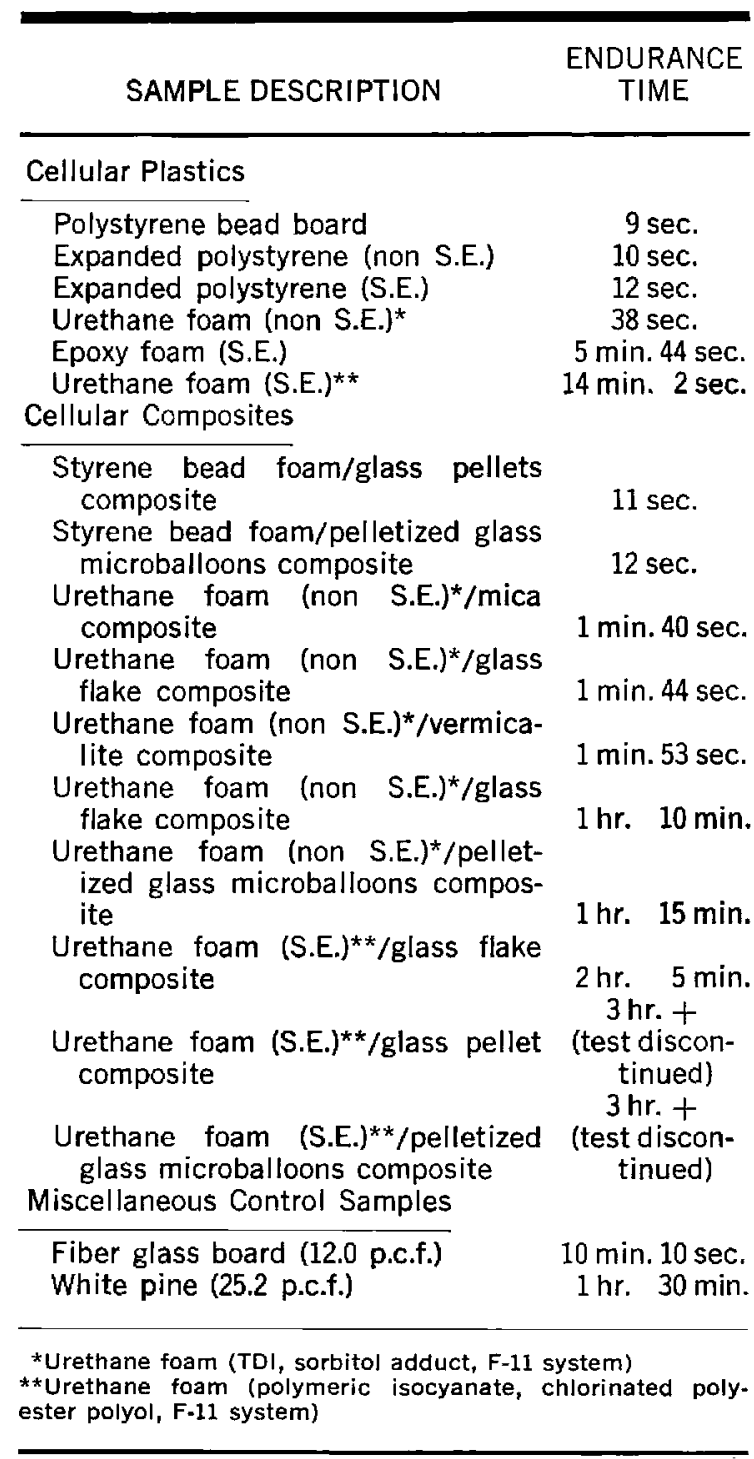

burner tip (designed to concentrate the flame source). The flame is adjusted to a cone of approximately $1.5^{\prime \prime}$ in length (temperature $2000^{\circ} \mathrm{F}$ $21004^{\circ} \mathrm{F}$ ) and the tip of the flame is positioned in contact with the sample surface at the beginning of the test. Failure, end of test, is indicated when the filter paper catches fire or chars and cracks.

A description of samples utilized in this study and test results are presented in Table 5.

Vertical Test-A schematic drawing of the Modified Bureau of Mines apparatus is illustrated in Figure 7.

The vertical test method is identical to the horizontal test method described previously except for positioning of the sample and the burner.

A description of the samples utilized in this study and test results (vertical method) are presented in Table 6.

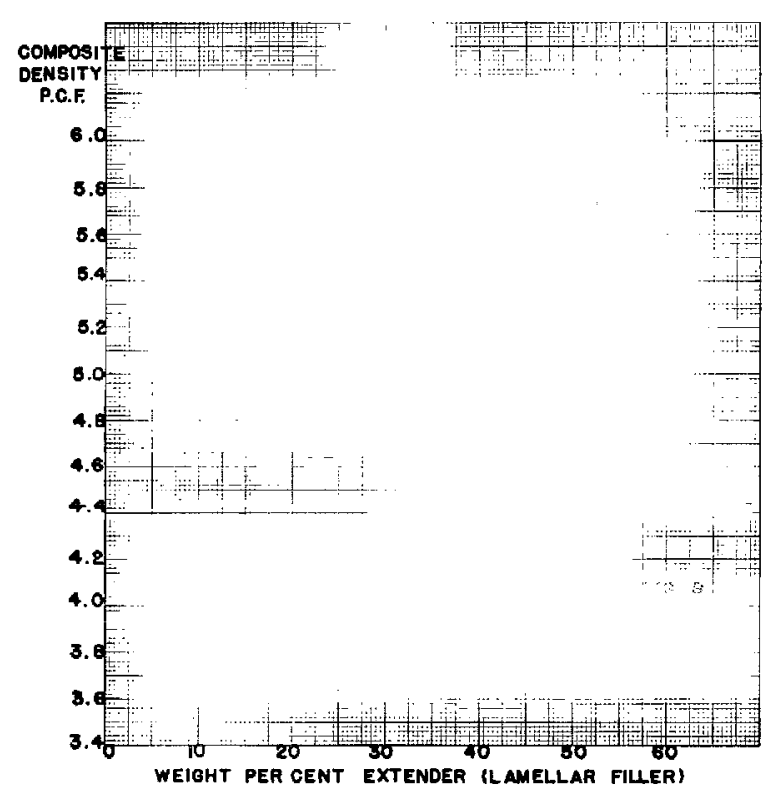

Figure 8. Relationship between extender loading volume and composite density.

\section{Summary of the Small Scale Fire Endurance Tests}

1. The horizontal test method was more severe than the vertical test method, thus only the results of the horizontal test will be reviewed.

2. All foams or foam composites based on expanded polystyrene (a thermoplastic material) failed in a very short period of time.

3. Composites based on inorganic lamellar extenders exhibited a slight improvement in fire endurance when compared to unfilled foams (20 seconds to 39 seconds). Marked improvement was observed when similar composites based on selfextinguishing formulations were compared to unfilled foams ( 3 hours plus to 19 minutes 20 seconds).

4. Composites based on inorganic fillers possessing moderate volume and good thermal conductivity characteristics exhibited substantially improved fire endurance characteristics when compared to unfilled foam (10 minutes 40 seconds compared to $20 \mathrm{sec}-$ onds for combustible systems, and 3 hours plus

Table 7. Tunnel Test (ASTM-E-84) Exploratory Results

\begin{tabular}{|c|c|c|c|}
\hline PROPERTY & $\begin{array}{l}\text { URE- } \\
\text { THANE } \\
\text { FOAM }\end{array}$ & $\begin{array}{c}\text { URETHANE* } \\
\text { FOAM/GLASS } \\
\text { FLAKE } \\
\text { COMPOSITE }\end{array}$ & $\begin{array}{c}\text { URETHANE* } \\
\text { FOAM/GLASS } \\
\text { PELLET } \\
\text { COMPOSITE }\end{array}$ \\
\hline $\begin{array}{l}\text { Propagation of } \\
\text { Flame Spread } \\
\text { Fuel Contribu- }\end{array}$ & 40 & 30 & $25-30$ \\
\hline $\begin{array}{l}\text { tion } \\
\text { Smoke Density }\end{array}$ & $\begin{array}{l}\text { N.M. } \\
+400\end{array}$ & $\begin{array}{r}10 \\
+400\end{array}$ & $\begin{array}{l}35 \\
65\end{array}$ \\
\hline
\end{tabular}

*Polymeric isocyanate, chlorinated polyester polyol, F-11 blowing agent. 


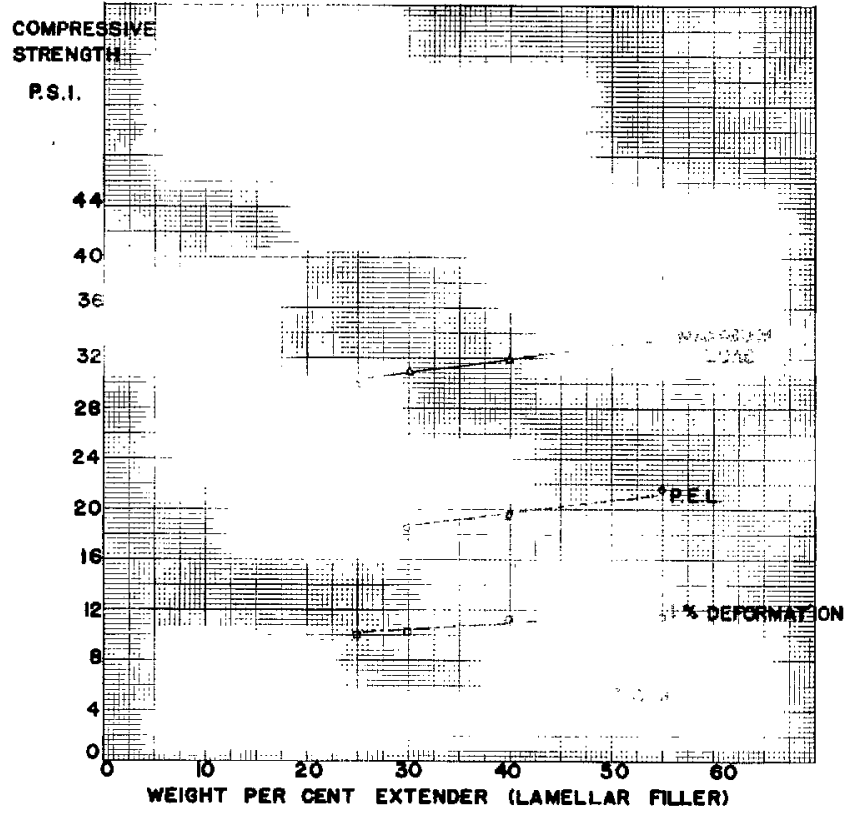

Figure 9. Relationship between extender loading volume and compasite compressive strength.

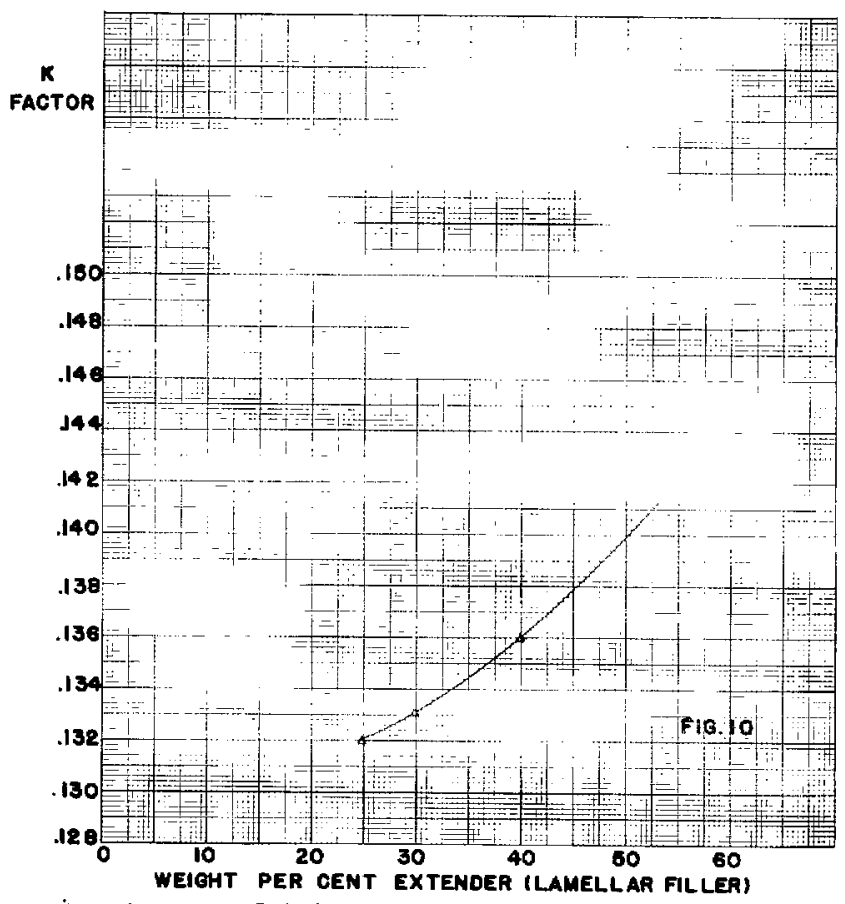

Figure 10. Relationship between extender loading volume and composite thermal conductivity.

compared to 19 minutes 20 seconds for self-extinguishing systems).

The evaluation of the fire endurance characteristics of cellular composites by a small scale bench test indicated the desirability of attaining additional information by recognized large scale test methods. A series of foams and composites were prepared by pilot plant techniques and the flammability properties determined by ASTM-E-84 (Tunnel Test).

Table 7 presents the results of exploratory tests conducted in the U.L. Tunncl.

A review of the data presented in Table 7 indi-
Table 8. Typical Properties of Pellet/Foam Composite

\begin{tabular}{|c|c|c|}
\hline Urethane system & \multicolumn{2}{|c|}{$\begin{array}{l}\text { Polymeric isocyanate, su- } \\
\text { crose adduct, Fluorocar- } \\
\text { bon-11 blowing agent }\end{array}$} \\
\hline Pellet size & $\bar{x}=0.4530$ & \\
\hline Pellet density & $\sigma=0.0045$ & \\
\hline Weight $\%$, pellets & 7.7 p.c.f. & \\
\hline Weight $\%$, foam & 69.0 & \\
\hline Volume loading, pellets & 31.0 & \\
\hline Volume loading, foam & 57.1 & \\
\hline Composite density & 42.9 & \\
\hline Foam density & 6.4 p.c.f. & \\
\hline WVTR (perm-inches) & 4.6 p.c.f. & \\
\hline $\begin{array}{l}\text { Compressive Strength, } \\
\text { p.s.i. }\end{array}$ & $\begin{array}{l}0.75 \\
\text { Initial }\end{array}$ & 4 Weeks W.R. \\
\hline $5 \%$ deflection & 42. & 28.4 \\
\hline $10 \%$ deflection & 56.7 & 42.6 \\
\hline P.E.L., p.s.i. at \% Defl. & 20.3 at 0.75 & 21.0 at 3.51 \\
\hline $\begin{array}{l}\text { Thermal conductivity @ } \\
75^{\circ} \mathrm{F} \text { Mean }\end{array}$ & 0145 & 0150 \\
\hline Dimensional stability, \% & 0.142 & \\
\hline $\begin{array}{l}\text { volume change } \\
\text { weeks in W.R. }\end{array}$ & +3.92 & N.C.* \\
\hline
\end{tabular}

*Tests not complete.

cates the major reduction in propagation of flame spread and smoke density characteristics obtained by the incorporation of inorganic extenders possessing moderate volume.

\section{Properties of Composites Based on Lamellar Extenders}

The density of the composites as well as the foam matrix is dependent on the type of extender and extender concentration. An indication of the relationship between composite density and concentration of extender (lamellar filler) is presented in Figure 8.

Only a slight increase in composite strength is observed as the concentration of extender (lamellar filler) is increased (Figure 9 ). An approximate $7 \%$ increase in thermal conductivity ( $K$-factor) was observed in foam composites based on lamellar fillers when the concentration of filler was increased from $25 \%$ to $55 \%$ by weight (Figure 10 ). Cellular composites based on lamellar fillers have measured water vapor transmission rates of less than 1 perminch. The rate of $\mathrm{K}$-factor deterioration in hot humid environments is less than that measured for unfilled organic foams.

\section{Properties of Composites Based on Inorganic Bulk Fillers}

Properties of a cellular composite extender with an inorganic bulk filler are presented in Table 8. The physical strength properties of composites based on bulk fillers depends greatly on the "packing volume" of the filler. The transfer of loads through such composites is indicated in Figure 11. Thus it can be shown that maximum strength can be obtained only if the extenders maintain point to point contact. 


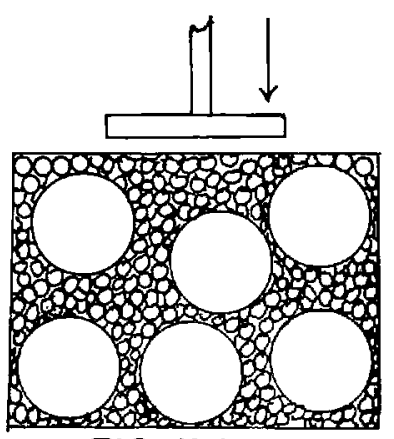

FIG. II A

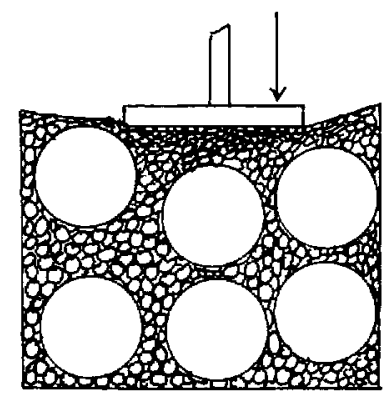

FIG. IIB

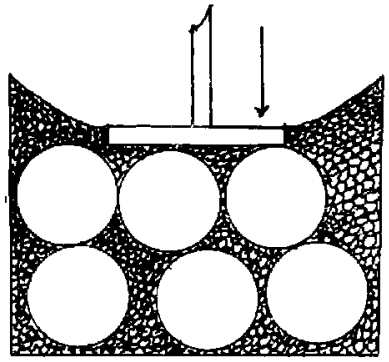

FIG. IIC

Low packing volume

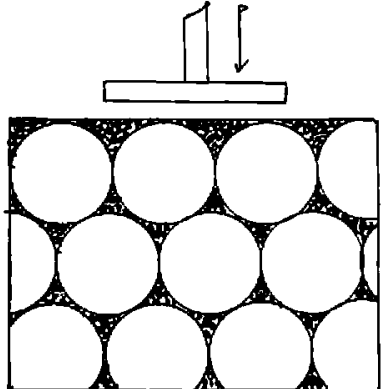

FIG. IID

Closest packing volume

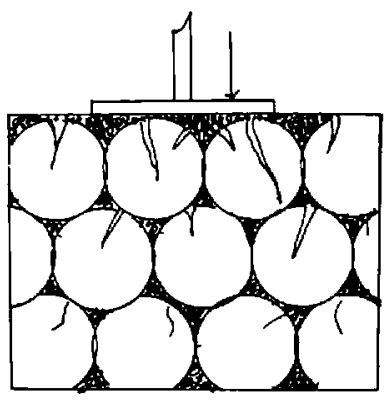

FIG. IIE

Figure 11. Effect of Extender Packing Volume on Composite Physical Properties.

\section{Conclusions}

The development of cellular composites based on low cost, bulk, inorganic fillers bonded together by char forming, fire retardant urethane foam has led to significant improvement of flammability characteristics. Low flame propagation rates, significant reduction in smoke density, and major improvements in fire endurance characteristics of this new class of materials should help to accelerate the rate of development and growth of cellular plastics in the building and construction industry. It would also appear feasible that the use of increased concentrations of low cost chemical extenders, such as wood derivatives, could be used to formulate foam systems which, while not possessing sufficient physical properties to merit consideration as foams, could be used as low cost matrix systems for cellular components.

\section{References}

1. Use of Lignin in Polyurethane Foams, Trade Bulletin, West Virginia Pulp and Paper Company.

Coglianese, F. A., and McCorkle, J. E., (To Johns-Mamville Corp.) Belgiun Patent 616,352 (April 12, 1962).

3. Vinsol (Trade mark, Hercules Powder Company), a dark colored, high melting thermoplastic material comprised of a complex mixture of compounds dexived from southern pine wnod. Phenolic constituents are present in the form of substituted phenolic ethers, polyphenols, and phenols of high molecular weight.

4. Hudson, G. A., (To Mobay Ohemical Co.), U.S. Patent $3,095,386$ (June 25, 1963).

5. Rigid Urethane Foam Derived From Crude Tall Oil, TIB 63-F25, Mobay Chemical Corporation.
6. Heiss, H. L. (To Mobay Chemical Co.), U.S. Patent 3,092,594 (June 4, I963)

7. Einhorn, I. "Evaluation of Flammability Characteristics of Cellular Plastics and Foam Composites". Presented at National Meeting of the Cellular Plastics Division, SPI, March 1963.

\section{N. Einhorn,}

Dr. Irving N. Einhorn received both his graduate and undergraduate degrees from Temple University, Philadelphia, $\mathrm{Pa}$. His industrial experience includes Project Manager for The Budd Co., Technical Director for the Industrial Plastics Div. of The Englander Co., Director of Research for the Wilmington Enamel-

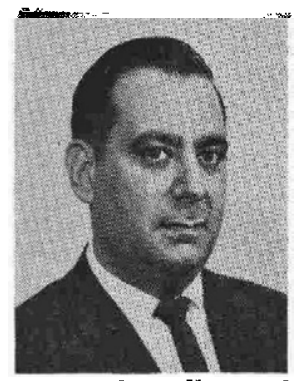
ing Div. of Seton Leather Co., Senior Research Fellow of Owens-Corning Fiberglas Corp., Manager of Corporate Foam Program for the same company. He is presently associated with The Institute of Science and Technology, The University of Michigan, Ann Arbor. He is a member of the policy committee of SPI, member of ACS, SPE and NACE, serving on the Review Board of the latter association's publication, Corrosion magazine. He was recently elected chairman of the newly formed Elasto-Plastics Division of SPI. Dr. Einhorn is also a member of the Editorial Advisory Board of the Joumal of Cellular Plastics. He is the author of numerous papers and patents on cellular plastics, organic coatings, and reinforced plastics. 